\title{
Report on the International Symposium on Quality of Care in China
}

November 17-19, 1999

Beijing, China

THE STATE FAMILY PLANNING COMMISSION OF CHINA

FORD FOUNDATION

(P Population Council 


\title{
Report on the
}

\section{International Symposium on Quality of Care in China}

\author{
November 17-19, 1999 \\ Beijing, China
}

THE STATE FAMILY PLANNING COMMISSION OF CHINA 


\section{(2) Population Council}

One Dag Hammarskjold Plaza

New York, New York 10017

tel 212-339-0500

fax 212-755-6052

e-mail pubinfo@popcouncil.org

wWw.popcouncil.org

The Population Council is an international, nonprofit, nongovernmental institution that seeks to improve the wellbeing and reproductive health of current and future generations around the world and to help achieve a humane, equitable, and sustainable balance between people and resources. The Council conducts biomedical, social science, and public health research and helps build research capacities in developing countries. Established in 1952, the Council is governed by an international board of trustees. Its New York headquarters supports a global network of regional and country offices.

Copyright @ 2000 by The Population Council, Inc.

Any part of this report may be copied or adapted to meet local needs without permission from the Population Council, provided that the parts copied are distributed free or at cost (not for profit) and that the source is identified. Any commercial reproduction requires prior permission from the Population Council. The Population Council would appreciate receiving a copy of any materials in which the text is used. 


\section{Contents}

Introduction 1

$\begin{array}{ll}\text { Opening Session } & 2\end{array}$

$\begin{array}{ll}\text { Keynote Speech } & 4\end{array}$

$\begin{array}{ll}\text { Session I: Concept and Practice of Quality of Care } & 7\end{array}$

$\begin{array}{ll}\text { Session II: IEC and Informed Choice } & 10\end{array}$

$\begin{array}{ll}\text { Session III: Reproductive Health Care } & 14\end{array}$

Session IV: Quality of Care in Less Developed Areas 16

Session V: Quality of Care in Urban Areas 20

Session VI: Monitoring, Information, and Management 23

Session VII: Challenges and Prospects 26

$\begin{array}{lr}\text { Plenary Session } & 29\end{array}$

Closing Session $\quad 32$

Appendix: Excerpts from Minister Zhang Weiqing's

Meeting with International Participants 34 



\section{Introduction}

In recent years, the pace of change in China has accelerated as the country has moved away from a centrally planned economy and toward a market-oriented one. Few institutions, including the family planning program, have been left untouched. At the same time, changes in the field of population and development, following international conferences in Cairo and Beijing, have made a deep impression on Chinese policymakers.

In 1995, China's State Family Planning Commission (SFPC), the governmental agency charged with developing and implementing China's population policy, issued an official call for the reorientation of the family planning program from a focus on demographic targets to meeting clients' needs. In support of this reorientation effort, the SFPC selected six rural counties and five urban districts with comparatively good socioeconomic conditions as pilot sites for a quality of care experiment.

This report provides a summary of an international symposium on quality of care held in Beijing from November 17 to 19, 1999. The symposium was sponsored by China's State Family Planning Commission with the support of the Ford Foundation as part of the international collaboration on China's quality of care initiative. The purpose of the symposium was threefold: to review the experiences of China's quality of care initiative in the pilot counties and districts to date; to discuss strategies for institutionalizing the quality of care approach in the pilot sites; and to discuss expansion and further development of the program throughout China, in keeping with the SFPC's decision that the quality of care experiment should be expanded nationwide.

Chinese participants in the symposium represented a diverse cross section of the Chinese family planning program. Representatives from the national, provincial, and county levels of the program were all in attendance, including leaders from the SFPC pilot sites. Also present were Chinese specialists from research institutions and universities who serve as members of the advisory group for the quality of care experiment.

International participants with a wide range of backgrounds and expertise took part in the symposium, serving as observers and commentators. Representatives from the Ford Foundation, the Population Council, the University of Michigan, and the International Council on Management of Population Programmes (ICOMP), the major international collaborators in China's quality of care initiative, were among those present. A special meeting of direct dialogue was arranged between 
Mr. Zhang Weiqing, the Minister of the SFPC, and the international participants, excerpts of which are included in the appendix.

China Population Information and Research Center staff played an instrumental role in the organization and coordination of the symposium. Baochang Gu, Senior Program Associate at the Population Council, and Rachel Goldberg, Staff Assistant at the Council, coordinated the international participation in the symposium. Diana Szatkowski, Consultant to the Council, served as rapporteur and prepared this summary report.

\section{Opening Session}

Zhang Yuqin, Vice Minister of the State Family Planning Commission, opened the International Symposium on Quality of Care in China. She extended a warm welcome to all the national and international participants, and thanked them for their hard work in support of China's effort to improve the quality of family planning services. She then reviewed the recent accomplishments of China's family planning program. Since the 1994 International Conference on Population and Development (ICPD), the Chinese Government has, in accordance with the ICPD spirit, made a number of important decisions on population and development. Based upon past practice in promoting family planning and the international experience in this regard, a new approach has been adopted throughout the country, which advocates two reorientations in the family planning program: (1) from focusing on family planning alone to an integrated approach that includes socioeconomic development; and (2) from implementing the program relying on administrative measures ${ }^{1}$ to introducing a new mechanism that combines incentives, publicity, comprehensive services, and scientific management.

The SFPC quality of care project has been an important measure in implementing the ICPD Programme of Action and the "two reorientations" in the family planning program. Since the SFPC initiated its quality of care project in 1995, there has been a rapid expansion in locally initiated quality of care projects. The delivery of high-quality services has brought about gratifying changes in the family planning program, with obvious improvement of the family planning workers' thinking and work-

\footnotetext{
${ }^{1}$ In the Chinese family planning program, the phrase "administrative measures" has been employed to refer to a vast array of family planning rules and regulations designed to ensure individual compliance with the government's population policies.
} 
ing style as well as their management level and quality. This has helped to consolidate the achievements in population control and to meet the increasing needs for family planning, and is warmly welcomed by the people and officials at the grass-roots level.

Andrew Watson, the Ford Foundation's Beijing Representative, gave an overview of the Foundation's programs in population and reproductive health over the past three decades, and its recent work in China. In the early years, the Ford Foundation's support was instrumental in setting up many of the world's leading organizations concerned with population issues. In the late 1980s, the Foundation made a major shift in its population strategy and program activities to support the provision of family planning services as part of an integrated women-centered approach to reproductive health improvement. The 1994 ICPD later endorsed this new vision. In the years since ICPD, the Ford Foundation has taken an active role in helping countries throughout the world implement the Cairo Programme of Action.

One of the most exciting developments post-ICPD has been the new service-oriented approach to family planning being promoted by the State Family Planning Commission. The Ford Foundation has supported the Quality Service Project since 1997. The service-oriented approach has since been expanded from the original six counties to hundreds of other counties in China. The popularity of the project with local women, family planning personnel, and county leadership speaks to their deep desire for change. Still, the challenges ahead for China to fully implement the new approach are great. Among the most important will be to set up an evaluation system that assesses cadre performance on the basis of quality service provision and client satisfaction. The international community is ready and willing to help China in this important endeavor.

George Brown, Vice President, International Programs Division, Population Council, began by extending his thanks to the SFPC for inviting the Population Council to participate, together with the University of Michigan, in China's pioneering effort to introduce a quality of care approach to family planning. He also thanked the Ford Foundation for its support of the project. Brown also mentioned the Council's early work in support of China's family planning program, such as support for biomedical research, contraceptive development and introduction, applied research and technical assistance in reproductive health, and biomedical and social science fellowships. He emphasized that the fundamental basis of quality of care is to place clients' concerns at the center. And moving away from targets and incentives is an important step in implementing a 
quality of care approach. The Population Council, along with the University of Michigan, is helping to develop evaluation systems (including new indicators of program performance) and improve information exchange. With respect to the latter, the Population Council recently helped host an Indo-China dialogue on making the transition to a clientcentered approach. The Council's approach is to search for common understandings while respecting the context in which such programs are implemented. Brown noted that the SFPC quality of care project is becoming a widely recognized example of change and experimentation in the world's largest family planning program. The Population Council looks forward to continuing its collaboration with the SFPC.

\section{Keynote Speech}

\section{China's Quality of Care Experiment in International Perspective}

Judith Bruce, Director of the Gender, Family, and Development Program within the International Programs Division of the Population Council, discussed three continuing challenges to delivering client-centered care in the post-Cairo and Beijing era: addressing clients' social context, responding to a broader spectrum of client needs, and measuring program results in terms of client-level outcomes.

Many programs around the world, including those in China, have often dealt with clients as if they were social isolates. While treating clients with appropriate privacy, the challenge is to develop an approach that allows them to deal with, and, if need be to discuss, certain aspects of their social context including, for example, marital or sexual partners' and families' attitudes. Providers must understand that clients' reproductive and sexual health is often not fully (or even substantially) under their own control. It is common for both clients and providers to find it difficult to talk about issues of power in intimate sexual relationships-but the door on the subject needs to be opened. As the contraceptive method mix expands-to include more barrier methods and a more equal balance of responsibility between women and men-the roles of power and differential male and female perspectives on intimate relationships can be increasingly acknowledged. Providers can play an important role in fostering a dialogue with clients about the perspectives of partners, other family members, and their community as a first step in developing a dialogue. Some of the pilot areas have already made efforts in this direction. 
As the program moves beyond family planning, and in the spirit of Cairo and Beijing, more attention needs to be directed to responding to a broader spectrum of client needs, such as addressing questions about sexual functioning; offering knowledge to help avoid, diagnose, and treat reproductive and sexually transmitted diseases; and engaging both the client and her partner in discussions of safe pregnancy, the health and social demands of the postpartum period, and the requirements of child survival. As the project is expanded into impoverished areas, family planning and reproductive health cannot be achieved without parallel poverty-reduction efforts. This broad-based approach can be appropriately linked in many areas with opportunities for income generation. Finally, as the family planning program moves toward a fee-for-service system, careful thought must be given to which standard services people can and should pay for, and which new services will be offered at what cost.

As programs shift their focus, so must evaluation criteria. Central to the new paradigm is elevating the attention given to client-level outcomes. What happens to clients' knowledge, satisfaction, and behavior as a result of new program approaches? Client outcomes could include: expanded knowledge of reproductive and sexual functions, increased capacity to care for and protect oneself, favorable changes in clients' or their partners' health-seeking behaviors, the ability to talk about sensitive matters with partners, access to a wider range of reproductive health technologies, increased knowledge of additional services and service points, and achievement of individual reproductive health goals.

Bruce noted some parallel changes fostered while offering client-centered services. When clients' needs are central, the value placed on information expands. Information by itself is power, and it is often the key "technology" that clients will need to protect themselves. A better-informed client should be a program end in itself. People must own information, not only because it is their right but also because in modern China they are increasingly mobile-their circumstances will change, and they will take information about their bodies and their health care with them wherever they go. Respecting and expanding the role of providers is also key to the success of the program. Their pride in their day-to-day work, and their improved relationship to their clients and communities are strong and essential supports to long-term quality of care efforts. The most important yet elusive challenge is to balance individual needs and rights with community resources. Bruce commended the Chinese participants for their achievements to date, and urged an increasing, and ultimately complete, separation of the roles of health care from the administration of the official 
birth planning policy. To the extent that China retains birth planning targets-which have never been applied throughout the country and seem to be being relaxed-it must be recognized that a client-centered approach cannot be fully achieved unless it emphasizes the rights of individuals above all, and offers them complete privacy and free discussions with health providers about their needs as they see them without external pressures.

\section{China's Quality of Care Experiment: Characteristics, Changes, and Challenges}

Zhang Erli, Deputy Secretary-General of the China Population Association and director of the SFPC's quality of care experiment from 1995 until his retirement in 1999, gave a broad overview of the development and implementation of China's quality of care experiment. He also discussed the changes that have been set in motion in the pilot sites, and the continuing challenges facing the project. Three important developments brought the issue of quality of care to the fore in China: stable low fertility (below the replacement level), the problems and opportunities that emerged with the development of a market economy, and international developments in the population field.

The experiment unfolded as follows. From early 1995 to late 1996, the project's goals were defined, the initial six pilot sites were selected, and a workplan was developed. From late 1996 to mid-1998, early achievements were consolidated, and five additional project sites were added. In mid-1998, an international contact group consisting of representatives from the SFPC, the Ford Foundation, the Population Council, and the University of Michigan was established.

The defining elements of the experiment have been its focus on comprehensive reform, its reliance on local resources, and its attention to local variation. The program has also adopted the following strategies: a "fade-in, fade-out" approach, a step-by-step approach, flexibility and diversity, and learning by practice. Several new mechanisms have been developed to carry out the experiment. They include: integrating family planning and public health services in some sites, integrating family planning management and service provision at the township level, setting up new management information systems to track clients' needs, and introducing fee-for-additionalservice systems. The activities that have been carried out in the project sites include: introducing informed choice, upgrading providers' technical and interpersonal skills, improving IEC efforts, strengthening service networks, expanding services from family planning to reproductive health care, and introducing reforms in the birth management system. 
Zhang noted, however, that challenges still remain. For example, the family planning program's capacity to carry out the quality of care experiment has not kept pace with the rapid expansion of local initiatives. To date, nearly 660 counties have adopted a quality of care approach. The new mechanisms to carry out the project also need to be refined. The existing SFPC pilot sites need more supervision and assistance, and new pilot sites in less developed areas should be added.

\section{Session I: Concept and Practice of Quality of Care}

In the first session of the symposium, directors of two provincial family planning commissions from provinces with large populations, and the deputy mayor from a city where one of the SFPC pilot counties is located, discussed the core elements of the quality of care project in their respective areas. They described the activities that had been carried out in support of the project and the results that had been achieved.

\section{Quality of Care in Family Planning: Considerations and Practice}

Chen Huiren, Director of the Jiangsu Family Planning Commission, enumerated the factors that necessitated the adoption of a quality of care approach in Jiangsu. The most important considerations were to meet the increasing demand for services, to improve IEC and provide timely and standard service, and to fulfill the commitment made by the Chinese Government at ICPD. The core elements of the quality of care project in Jiangsu include: providing comprehensive contraceptive services, providing basic reproductive health care services, and integrating family planning services with economic development and women's empowerment activities. A number of activities have been carried out in support of the effort to improve service quality. A computerized network that links provincial, county, and township-level family planning departments has been set up. Clinic facilities have been upgraded. Providers have been trained, and standards have been developed to guide practice.

A number of achievements have been realized in the five years since the quality of care approach was first introduced in Jiangsu. The commitment made by the Chinese Government at ICPD has been fulfilled. The underlying ideology and practice of the family planning program have been changed. Client satisfaction has increased, and contraceptive use and effectiveness have improved. The goal is that by the year 2010 eligible 
clients should have access to comprehensive contraceptive and reproductive health care services.

\section{Concept and Practice of Quality of Care in Family Planning}

Jiang Jun, Deputy Mayor of Liaoyang City in Liaoning Province, discussed the implementation of the quality of care approach in Liaoyang. He attributed the success of the project to its adoption of a "step-by-step" approach. In 1997, the project began in three relatively developed counties with good program performance. Based on the lessons learned from these first pilots, the quality of care project was then introduced in a second group of counties. Finally, the project was implemented in the remaining counties. Jiang then discussed two key features of the quality of care project in Liaoyang: (1) its emphasis on coordination between the public health and family planning sectors; and (2) its emphasis on educational efforts to increase levels of family planning and reproductive health knowledge. With regard to the former, hospitals, which are under the jurisdiction of the health department, now provide family planning as well as reproductive health care services. With regard to the latter, a variety of efforts have been undertaken to increase people's knowledge of family planning and reproductive health, including recruiting and training volunteers to provide face-to-face counseling, and selecting families to assist in service delivery. After three years, the project has registered a number of achievements: the rate of out-of-plan pregnancies has decreased by 46 percent; ${ }^{2}$ 90 percent of childbearing women have participated in the informed choice program; and 85 percent of women of childbearing age express satisfaction with the services that have been provided. Moreover, the relationship between family planning workers and clients has improved.

\section{Quality of Care Experiments in Shandong Province}

Li Hanzhang, Deputy Director of the Family Planning Commission of Shandong Province, discussed the achievements of the quality of care program in the province. Contrary to the expectations of some who believed that the birth rate would rise after the introduction of the new approach, the birth rate has remained stable and even decreased in some areas. For example, Weihai City is projected to have a negative growth rate by the year 2005. Doorstep delivery of contraceptives has improved, as has follow-up after contraceptive surgery. In Jianan, for instance, 80 percent of

${ }^{2}$ The rate of out-of-plan pregnancies refers to the percentage of pregnancies inconsistent with local family planning policy. 
families receive doorstep delivery of contraceptives compared to 50 percent before the introduction of the program, and 100 percent have received follow-up visits after contraceptive surgery as compared to 52 percent before. People's reproductive health knowledge has also increased. In Jianan, for instance, the proportion of women who realize the necessity of periodic checkups has increased from 62 percent to 93 percent. Finally, the proportion of family planning workers with postsecondary education has increased by 11 percent since 1995 .

\section{Discussion and Comments}

The discussion that followed the presentations focused on ways to promote the sustainability of quality of care projects. Participants discussed the role of user fees in financing such projects. Chen Huiren noted that in Jiangsu, basic contraceptive services are free, but that a fee is charged when additional services are required. Jiang Jun added that he thought quality of care could survive in the future because people were willing to pay for high-quality services. He noted that the fact that such a program had been carried out in Liaoyang, a city that had experienced economic difficulties, should serve as inspiration for less developed areas that are thinking about introducing a quality of care approach. Other participants commented on the relationship between the public health and family planning sectors. Some argued that integrated services are more cost-effective; others argued that the two sectors serve different target populations and should remain separate.

Ruth Simmons, Professor of Health Behavior and Health Education at the University of Michigan School of Public Health, commented on the progress that has been achieved to date in China's quality of care transition. The shift from a focus on population targets and tight management control to a client-centered approach that focuses on reproductive needs and rights implies a fundamental transformation of the program. She noted that from the presentations and from her own participation in the assessment of the experiment last year, such a transformation is indeed underway. Citing a German saying that if you do not know the goal, you cannot find the way, she commented that the Chinese working in this field clearly know their new goal and are finding constructive ways of reaching it.

Simmons noted that four factors are central to explaining the success of the Chinese quality of care experiment: (1) understanding that a fundamental change in values and philosophy is required to implement the new approach; (2) recognition of the critical role of leadership in making this change; (3) emphasis on system-wide change; and (4) attention to the diverse contexts in which the new approach is being introduced. She also 
noted that the presentations at the symposium made clear that there is a feeling that the quality of care transition is incomplete, which is not surprising since quality of care reform is a process that takes time to accomplish. A thousand-mile journey starts with a single step. Many steps have already been taken, and it is appropriate to proceed in this incremental manner.

Three questions are likely to be asked about the quality of care experiment: (1) Will it be possible to make further improvements in the 11 rural counties and urban districts that participated in the experiment? (2) Are the accomplishments sustainable? (3) Can the experiment be expanded to other parts of the country, especially to poorer regions? Simmons believed that the answer to these questions would be yes if the project continued with the same motivation and commitment, the same systems focus, and the same participatory learning approach that had characterized the experiment until now. Simmons noted that in many successful experimental projects, questions about sustainability and project expansion are the most difficult ones to answer. People are often quite nervous when such questions are raised. In the case of China, however, one can be quite optimistic because the experiment has been undertaken with local resources, local initiative, and skillful national guidance. Liaoyang County is one of the poorer counties. The fact that it was possible to initiate the quality of care experiment there tells us that one can begin to think about expansion to other poor areas as well. In conclusion, Simmons expressed her appreciation for the opportunity to be part of the assessment last year and noted how impressed she was with the counties' openness to the new assessment methodology.

Gao Ersheng, Director of the Shanghai Planned Parenthood Research Institute, argued that attention must be paid to the local context when introducing a quality of care approach. In China, where resources are limited, ideological change is the most important. The goal of the family planning program should be to meet clients' needs as well as demographic goals, and attention should be directed to meeting men's reproductive health needs as well as those of childbearing women. In support of the latter, Gao related the case of a woman who was repeatedly treated for a reproductive tract infection. Not until she had been treated several times was it discovered that her husband was the source of her repeated infection.

\section{Session II: IEC and Informed Choice}

In the second session, the leaders of two of the SFPC pilot counties, Nong'an County of Jilin Province, located in northern China, and Deqing 
County of Zhejiang Province, located in southern China, discussed the innovations that had been introduced in their respective family planning programs in the areas of IEC and informed choice. In addition, a researcher from the Jiangsu Family Planning Research Institute reported the results of a study that employed a quasi-experimental design to investigate the impact of improved quality of care on the acceptability and use-effectiveness of contraceptive methods in two counties in Jiangsu Province.

\section{IEC Before and After the Introduction of the Quality of Care Experiment}

Hu Yamin, Director of the Nong'an County Family Planning Commission in Jilin Province, noted that before the introduction of the quality of care experiment, IEC materials contained little practical information about contraception and reproductive health. Instead, IEC brochures focused on population policy and regulations. People found them boring and irrelevant; children used them to make paper airplanes, and adults to roll cigarettes. After the introduction of the experiment, the Family Planning Commission worked hard to change the form and content of IEC materials, and to expand the target audience to include men and adolescents. More attention has been paid to providing detailed information about contraception in an attractive and easy-to-read format. Mobile outreach teams now visit the villages and hold talks on reproductive health matters. They also visit clients in their homes. When they do, they bring along the "informed choice display box" and "reproductive health care packages." When they first designed the display box, it was unwieldy. The design has since been modified to make it more portable. Now people ask more questions. They also keep their IEC materials with their clinic registration cards instead of using them for other purposes.

\section{Promoting Informed Choice}

Shao Huimin, Director of the Deqing County Family Planning Commission in Zhejiang Province, noted that before the introduction of the quality of care experiment, few method choices were available to users in Deqing. As in many other places throughout China, the rule was "IUD after the first birth, and sterilization after the second." Given this situation, grassroots family planning workers and county leaders were eager to promote informed choice. Women also welcomed a change. However, township leaders were concerned that the rate of out-of-plan 
pregnancies might rise if they were to adopt the new approach. A county leader characterized the situation as "hot at two ends, but cold in the middle." To address the township leaders' concerns, a small-scale experiment was conducted in one village to introduce informed choice. All women who participated in the experiment were given a choice of at least three methods and were fully informed of the methods' use and effects. The majority of these women chose highly effective long-acting methods. After this successful trial, informed choice was gradually expanded to the county at large.

Shao noted that since the start of the experiment, the contraceptivemix in Deqing has broadened considerably, while demographic rates have remained stable. In 1994, 43.5 percent of all users were sterilized, and 45.7 percent of users relied on the IUD; 6.3 percent of users reported pill use, and 3.8 percent used condoms. In September 1999, 35.8 percent of all users were sterilized, 50.8 percent relied on the IUD, 4.0 percent reported pill use and 8.8 percent used condoms. At the same time, Shao reported that fertility and out-of-plan pregnancy rates have remained low, and contraceptive prevalence has remained high.

\section{The Impact of Improved Quality of Care on the Acceptability and Use-Effectiveness of Contraceptive Methods}

Li Ying, Research Scientist at the Jiangsu Family Planning Research Institute in Nanjing, reported that the objective of their study, which was funded by the World Health Organization, the SFPC, and the Jiangsu Science and Technology Commission, was to evaluate the impact of improved quality of care on the acceptability and use-effectiveness of contraceptive methods in two areas in southern and northern Jiangsu. Four villages were selected as experimental areas, and four villages with comparable socioeconomic and health conditions as control areas. In the experimental areas a comprehensive intervention to improve quality of care was introduced. The degree of satisfaction, the incidence of induced abortion, and the continuation rates in the experimental areas were then compared with those in the control areas.

Li noted that the levels of satisfaction were found to be higher, and

the incidence of abortion lower in the experimental areas as compared to the control areas. In the experimental areas, 81.2 percent of women expressed satisfaction with the contraceptive methods currently used, whereas in the control areas only 71.6 percent of women did. In the experimental areas, 5.7 percent of women had had an abortion since the study began, whereas in the control areas the percentage was 11.8 per- 
cent. Continuation rates were also higher in the experimental areas than in the control areas.

\section{Discussion and Comments}

Participants commented on the broadening of the method-mix, especially the increase in condom use, and asked for details about the new condom users. Shao Huimin responded that in Deqing the new condom users fell largely into two groups: those who wanted to delay the first birth and those who were switching methods.

Another participant asked about male involvement in family planning. Hu Yamin admitted that, at first, the importance of male involvement was overlooked in Nong'an. Only in the course of implementing the client-centered program was its importance realized. He also recounted how shy the men had been when family planning workers first discussed condom use. Now, they are becoming more accustomed to the idea.

Iqbal Shah, Scientist in the Department of Reproductive Health and Research at the World Health Organization (WHO), recalled his first trip to China in 1985 and the changes that had taken place since then. Shah visited China in 1985 for the very first WHO-supported social science study in China, "Contraceptive Variation in Rural Jiangsu." Since then he has seen the transformation of China in all aspects of life, including family planning. Indeed, in the mid-1980s, the leaders, providers, or workers with whom he met never mentioned quality of care or users' needs. He noted that it is very gratifying to see that a new study in the same province, by someone who was involved in the first WHO study, has provided solid scientific evidence for the impact of improvements in quality of care on contraceptive continuation, user satisfaction, and abortion incidence.

Shah then discussed the new role of IEC. While the concept of IEC is not new, its redefined role in the context of informed choice and quality of care is a dramatic departure from past practice. IEC used to be viewed by many family planning programs as a means to meet family planning targets. IEC has now acquired a more respectable and critical role in helping clients make informed choices based on their needs and preferences.

Wu Shangchun, Associate Professor at the National Research Institute for Family Planning, made a plea for increased attention to upgrading providers' contraceptive knowledge and counseling skills. She related two examples that underscored the critical need for addressing provider misunderstandings about contraceptive use. One case concerned the head of a large municipal hospital who insisted that the use of oral contraceptives would lead to infertility. The other case involved an institution that pro- 
moted an outdated IUD because it wanted to reduce its existing stock before introducing a new IUD. Another important issue is that some providers insist that it is their duty to provide moral instruction to clients. In one instance, an unmarried couple who had come to a clinic for contraceptives were turned away after receiving a lecture on the immorality of engaging in sexual activity outside of marriage.

\section{Session III: Reproductive Health Care}

In the third session, county leaders from three regions discussed the efforts that had been made in their respective regions to expand the scope of reproductive health services, the factors that had prompted them to do so, and some of the results that had been achieved.

\section{Providing Reproductive Health Services to Promote the Reorientation of the Family Planning Program}

Li Yixin, of Zhongxiang County in Hubei Province, described eight kinds of services that have been introduced to promote the "two reorientations" in the family planning program: premarital education; infertility diagnosis and treatment; genetic screening for birth defects; routine screening tests; informed choice; children's health care; women's health care services; and services for menopausal women. Significant effort has been devoted to developing facilities and acquiring technologies to carry out these services. For example, Zhongxiang Hospital set up a special department for the diagnosis and treatment of infertility. To carry out genetic screening, a cell inheritance lab was established, and advanced instruments such as equipment for conducting laser therapy have also been acquired. As a result of these efforts, Li noted, a number of rates have reached new highs: the informed choice rate is 96 percent; the contraceptive rate is 95 percent; and the premarital consultation rate is 98 percent. At the same time, other rates have dropped. The neonatal mortality rate is below 1 percent, and less than 5 percent of babies are born with birth defects.

\section{Developing Primary Health Care to Promote Quality of Care in Family Planning}

Zhang Jinzhu, of Qiqihar in Heilongjiang Province, described how reproductive health services were introduced to the family planning program in Qiqihar. In 1996 and 1997, four counties selected three villages each; all other counties selected one village. In 1998, the program was expanded to 
50 percent of the counties. In 1999 and 2000, the program will be expanded to the remaining counties.

An important feature of the family planning program in Qiqihar is the way in which it collaborates with the health department and women's organizations to meet women's reproductive health needs. Each has its own expertise. The family planning program has an extensive network, the health department has facilities and personnel with special skills, and women's organizations have experience in disseminating information to women. Together they have worked to provide examinations and lowcost treatments for reproductive tract infections, ${ }^{3}$ to promote healthy births, and to provide prenatal and postnatal care. Contraceptive prevalence now stands at 90 percent, and files have been set up for 97 percent of clients of reproductive age.

\section{Providing Reproductive Health Care Services}

$\mathrm{Hu}$ Lijun, of Rongcheng County in Shandong Province, described some of the efforts to broaden the scope of services and improve their quality, such as improving the provision of contraceptive services; expanding healthy childbearing services; and promoting the systematic delivery of reproductive health care services. In support of these efforts, new staff have been recruited, existing staff have been retrained, and facilities have been constructed or renovated. As a result of these efforts, Hu noted, contraceptive use-effectiveness has improved (the failure rate now stands at 2 percent), reproductive health has improved, and the incidence of birth defects has declined. Still, the capacity of service providers to deliver high-quality care is relatively weak. Lack of standardized services is also a problem.

\section{Discussion and Comments}

The presenters were asked to elaborate on some of the statistical data they had presented. Specifically, Zhang Jinzhu was asked what he meant when he referred to a contraceptive prevalence rate (CPR) of 90 percent. Zhang replied that the CPR in fact referred to those people who were required to practice contraception. Another question referred to the claim that contraceptive failure rates were 2 percent, to which $\mathrm{Hu}$ Lijun replied that the fail-

\footnotetext{
${ }^{3}$ Reproductive tract infections (RTIs) are often called or translated as "women's diseases" in China, perpetuating the false and offensive notion that these diseases, which afflict both men and women and are actually more easily transmitted from men to women, are women's special responsibility. This conceptualization, and the blaming of women for such infections, has often limited attention to them. Happily, this is now changing.
} 
ure rate for condoms and oral pills was indeed very low-around 2 percent. Iqbal Shah added that some of the confusion about rates might be related to the fact that in China the denominator used for calculation of the CPR refers to those who are required to use contraception, and that therefore it is theoretically possible to have a rate approaching 100 percent.

Christopher Elias, Senior Program Associate at the Population Council, noted that while this was only his second visit to Beijing, and his first opportunity to meet with representatives from the SFPC, it was evident from the presentations and discussions that change was underway in the Chinese family planning program. He also interjected a cautionary note, saying that the session on Reproductive Health Care had highlighted the work that remains to be done in expanding the scope of services beyond family planning.

Particular attention must be paid, he continued, to the rapid proliferation of treatments and technologies, especially their relationship to the service system in which they are deployed. There is, for example, much confusion about RTIs, which are both overdiagnosed and overtreated. The confusion is compounded when RTIs are referred to as "women's diseases." In fact, men have them too, and this has to be kept in mind. It is also important for providers to understand that some RTIs are sexually transmitted and some are not. Overtreatment of RTIs with antibiotics is expensive and may cause resistance to such drugs. Other technologies, like laser treatment, are very aggressive. It is important to keep our attention focused on the client and to take a cautionary approach to the introduction of new technologies.

Liu Wei, of the Yunnan Reproductive Health Research Association, noted that since the presentations in this session discussed the development of reproductive health programs in three areas with different levels of economic development, they provided valuable experience for expanding the quality of care approach to other areas. He added, however, that the Western areas of China might be a special case. There, levels of economic development are especially low and the culture is quite different. It is most useful to learn from those who have already introduced quality of care projects what difficulties they encountered and how they addressed these problems. When this experience is known, others may learn from it, he concluded.

\section{Session IV: Quality of Care in Less Developed Areas}

In the fourth session, county leaders from two poor rural areas in central China, Liuyang County in Hunan Province (which was in the second 
group of SFPC pilot sites) and Bazhong County in Sichuan Province, discussed the special challenges of implementing quality of care projects in less developed areas. In addition, a researcher from the Yunnan Reproductive Health Research Association in southwest China discussed women's perspectives on family planning and reproductive health. The integration of family planning with poverty alleviation was an important theme in the session.

\section{Promoting Quality of Care in Poor Rural Areas}

Li Jiaxi, Director of the Liuyang County Family Planning Commission in Hunan Province, noted that in 1997, the Commission conducted a survey of 509 women of childbearing age to assess their reproductive health needs. Of the 509 women, 89 expressed a need for information on contraceptives, 175 a need for information about childbearing and rearing, 351 a need for general health information, 157 a need for information on income-generating skills, and 209 for information on maintaining a harmonious household. In terms of their needs for services, 107 of the women expressed a need for treatment for surgical complications, 252 a need for maternal health care, 378 a need for contraceptive services, and 407 a need for treatment of reproductive tract infections.

Li noted that, based on this information, they proceeded in a step-bystep fashion to implement the quality of care project in Liuyang County. In 1997, 17 villages with a total population of 25,827 carried out the quality of care experiment; in 1998, 83 villages with a total population of 117,492 did; and in 1999, the entire county did so-222 villages with a total population of 305,674 . He noted that they also distinguished between three levels of services. For the first level, basic reproductive health services were provided in all pilot sites. For the second level, informed choice of contraceptives was introduced to a select group of townships. During this time, fertility contracts and deposits for IUDs and sterilization were abolished. Finally, for the third level, "birth management requirements" were removed in four towns and townships. By doing this they have worked to gradually meet the reproductive health needs of the people. However, many challenges remain, including inadequate financing, increased demands for services, poorly trained providers, and an inadequate monitoring and evaluation system.

Quality of Care in Poor Mountainous Areas

Zhang Yuxiang, Director of the Bazhong County Family Planning Commission in Sichuan Province, described a program introduced in 
Bazhong called "Fewer Births and Speedy Richness." A number of activities have been carried out under this program, such as setting up 3,450 mutual assistance groups, giving family planning acceptors preference for a variety of services, and organizing poverty-alleviation efforts. The Commission has also worked to increase people's knowledge of family planning and reproductive health in a variety of ways, such as setting up a premarital education class, airing a television program on reproductive health matters, and setting up a "Family Activity Center." Zhang noted that from their own experience they found that the key elements to implementing a quality of care approach are, first, to ensure that cadres have a strong awareness of quality of care concepts and principles; second, to set up a good family planning and reproductive health service network; and third, to make sure there are sufficient qualified providers to carry out the program. Since the "Fewer Births and Speedy Richness" Program has been introduced, client satisfaction has risen from 84 percent to 94 percent, and the family planning rate has gone from 92 percent to 95 percent.

\section{Women's Perspectives on Family Planning and Reproductive Health in Yunnan}

Fang Jing, of the Yunnan Reproductive Health Research Association, discussed women's perspectives on family planning and reproductive health in Yunnan Province, a poor province in southwest China with a large minority population. Poor women in Yunnan tend to have little formal education, and they are at times suspicious of modern contraception. They need educational materials that are easy to understand. In the past women often complained that IEC materials were difficult to comprehend. Now, poor women have been invited to participate in the design of IEC materials, and better results have been obtained.

Poor women in Yunnan also like to make their own contraceptive choices. For example, in Shuangba village in Dazhuang County, a poor minority county, the majority of couples choose vasectomy. They give various reasons for doing so, including the fact that women are an important source of labor and that it takes women longer than men to recover from a sterilization operation. Women also express a need for better reproductive health care services. Access to clinics is often difficult and follow-up is poor.

Fang concluded by offering some suggestions for practicing quality of care in resource-poor environments such as Yunnan. Greater effort should be made to increase communication with poor women through the use of participatory methods. Husbands, who usually have more education than 
their wives, should help explain contraceptive use to their wives. Finally, greater efforts should be made to improve coordination and foster collaboration between family planning and public health departments.

\section{Discussion and Comments}

Participants first debated the role of poverty-alleviation efforts in quality of care programs in less developed areas. Zhang Yuxiang said that, in Bazhong County in rural Sichuan, attention was paid to poverty-alleviation efforts for two reasons: (1) SFPC regulations required them to do so; and (2) it would be impossible to improve people's health without addressing their economic situation. Li Jiaxi then described two povertyalleviation efforts that are underway in Liuyang County in Hunan Province. The first involves making "family planning insurance" available for families with two girls. The second organizes income-generation activities for needy households. Discussion then shifted to meeting the needs of the "floating population." Li Jiaxi said that in Liuyang County they work to meet migrants' needs in two ways: (1) they help out-migrants get their paperwork ready so that they can obtain services in other areas; and (2) they provide round-the-clock services to in-migrants.

Saroj Pachauri, Regional Director of the South and East Asia program at the Population Council in New Delhi, expressed sincere thanks for the invitation to attend the symposium and commented on the importance of China's quality of care experiment for the developing world at large. While many countries are taking steps to implement the Cairo Agenda, there are many ways that this can be done. Some choose to make policy changes first. In China, changes are first being introduced to the program. Improving quality of care in South Asia is a challenge. Not only is there a strong patriarchal system, there are also many bureaucratic hurdles to be overcome. And people's needs are great. It is important to design services that are based on the needs that clients themselves have articulated. Evaluation systems, too, should give clients a voice, and not only serve administrative functions. Finally, it is important to create a demand for quality, for, as many studies have shown, even when quality is poor clients still express satisfaction.

Zhu Chuzhu, Professor at the Population Institute of Xi'an Jiaotong University, said that more attention should be paid to meeting the needs of women in poor rural areas and particular attention should be devoted to developing low-literacy materials. She also voiced support for the integration of family planning with poverty-alleviation efforts. She noted that to succeed in both endeavors would be a great revolution. 


\section{Session V: Quality of Care in Urban Areas}

In the fifth session, district/county leaders from three large cities in north China, Beijing, Tianjin, and Qingdao, the first two of which were in the second group of SFPC pilot sites, discussed some of the challenges of carrying out quality of care projects in urban areas. These challenges include meeting the needs of a diverse clientele, making do with shortages of space and personnel, and providing high-quality services at reasonable costs. They also discussed some of the efforts that had been made to meet these challenges, such as integrating family planning and other health-related services, and developing management information systems to track clients' needs.

\section{Integration of Family Planning with Community-Based Health Services}

Guo Xinhua, Director of the Family Planning Commission in the Xuanwu District of Beijing, noted that the decision to integrate family planning services with community-based health services was motivated by several factors: (1) increasing demand for high-quality family planning and reproductive health services, (2) the relative abundance of medical resources in the public health sector, and (3) their mutual goal of providing individuals and families with comprehensive, high-quality health care.

Several activities have been carried out in support of the integration effort. For example, volunteer teams composed largely of retired health professionals have been organized to provide counseling and treatment free of charge; gynecologists have been invited to supervise family planning services and solve technical problems; and workshops have been held to disseminate reproductive health care knowledge. A variety of services are now provided, which include diagnosis and treatment of gynecological diseases, infertility treatment, and services for newlyweds on safe sex, healthy childbirth, and prenatal care. As a result of these efforts, clients are receiving convenient, high-quality services, and the collective resources are being used more efficiently. Still, service providers from both the family planning and public health sectors need to continue to update their knowledge and technical skill. Leaders and managers must try hard to maintain a client-oriented perspective, and community-based facilities need further improvement.

\section{Using the Management Information System (MIS) to Meet Clients' Needs}

Wang Xiulan, Director of the Family Planning Commission for the Heping District of Tianjin, noted that the Commission comprises the follow- 
ing work units: the reception office, the district service center and subcenters, the district IEC center, the contraceptive supply stations, and the citizens' committees' service stations. Together, these working units provide policy counseling, childbearing services, education and physical examinations for newlyweds, counseling services, contraceptive supplies, IEC materials, the Citizens' Handbook, and the Handbook of Quality of Care.

To assess clients' needs, the Commission relies on information collected from field surveys and from the work units. They have been able to identify the kinds of reproductive health and administrative services for which people come to the clinic, as well as the types of counseling services they receive. Based on this information, they developed materials to meet the demand for reproductive health care information. To meet the needs of particular groups, they have developed activities such as job training for unemployed workers, classes on newborn care for new parents, and infertility and menopausal counseling for women who suffer from these conditions. Since the services that they offer are geared toward clients' particular needs, the availability of these services has led to increased participation in family planning and reproductive health activities.

\section{Integration of Family Planning and Medical Care}

Feng Qingcai, Deputy Director of the Qingdao Family Planning Commission in Shandong Province, noted that, as in Beijing, efforts are underway in Qingdao to integrate family planning and public health services for the purposes of reducing waste and inefficiency and providing a broader array of services. Unlike Beijing, however, a new structure, the Department of Reproductive Health Care, was created in Qingdao to carry out these new functions. Feng noted that two other important changes were introduced in Qingdao: competitive recruitment and training programs and a fee-for-additional-services system. These two reforms have resulted in a 267 percent rise in the number of technical providers and a 58 percent rise in the revenue generated since the start of the project. Similar to what is being done in Beijing, a wide variety of services are now being offered: prenatal and postpartum care, infant and child health care, treatment for common reproductive diseases, and infertility treatment. Ninety percent of clients now report satisfaction with services, compared to 81 percent before the Department of Reproductive Health Care was established.

\section{Discussion and Comments}

Participants commented on the efforts that had been made to integrate family planning and public health services and the role of user fees. They 
also touched on the issue of educational programs for adolescents and young adults. One participant asked how it had been possible to get managers from the two sectors to sit down and discuss matters. Guo Xinhua responded that in Beijing it had been relatively easy since both departments were under the leadership of the local government. It was the local government, not the family planning or public health sectors, that made the integration possible. Discussion then turned to the issue of user fees, with some arguing for their introduction and others urging caution. Some argued that if the newest and best services were desired, a fee should be imposed. Others were concerned that a two-track system might be created where some had access to better-quality services and some did not. Another participant voiced concern that women were particularly vulnerable since they have, on average, less money. Finally, there was a brief discussion of the availability and content of educational programs for adolescents and young adults. Wang Xiulan said that in Tianjin ongoing programs are available for high-school students, but not for college students. Xu Baozheng, Director of the Family Planning Commission for the Luwan District of Shanghai, said that, in Shanghai, the education department and not the family planning department provides adolescent health education. Liu Wei added that, in Yunnan, education efforts are focused on STDs and AIDS, and that peer education is an important part of the program.

Praema Raghavan-Gilbert, Chief Technical Advisor for the United Nations Population Fund (UNFPA) in Beijing, commented that managers everywhere are struggling with the concept of service quality. She traced the origins of the quality movement, which started in industry after World War II with the primary objective of reducing waste and increasing profits. Health care is a very late entrant to the quality movement. This is because the clinicians who traditionally ran the health care industry believed its role to be "different." She noted that while the client-centered focus was important, it was not sufficient for ensuring high-quality services. This is because clients are often unaware of the deficiencies in the health care system. She stressed that the management focus was equally important because only the organization (management) had all this information and the means to correct it.

She said that research has shown that the process of improving quality is slow and incremental and often takes up to six years to institutionalize. This process calls for a long-term sustained political commitment to quality at the policy level, which in turn needs good data on quality for decisionmaking. Good data are difficult to find because of inherent prob- 
lems in both defining and measuring quality from different perspectives of numerous stakeholders. Clients tend to value reliability and empathy; providers rate technical competence and facilities highly; and donors find efficiency and impact important. Raghavan-Gilbert concluded that extensive research is needed in this area of service utilization.

Zheng Zhenzhen, Associate Professor at the Population Institute of Peking University, commented on three issues: the unique challenges of implementing quality of care projects in urban areas, the lack of attention to "care" in Chinese definitions of quality of care, and the issue of adolescent education. Urban areas present special challenges. The population is more diverse, and their demands are greater and more difficult to satisfy. These issues must be taken into account in developing programs to address the needs of urban areas. Zheng noted that when the phrase "quality of care" is translated into Chinese, something is lost-namely, the emphasis on care. Quality of care is, after all, more than delivering high-

quality technical services. There is an interpersonal dimension as well, and one needs to pay more attention to this aspect. Zheng also discussed adolescent issues. It is not difficult to have educational programs for adolescents. What is most important, however, is that there be discussion about the content of these programs. She noted that when her daughter was in middle school the students were taught about physiological development and the development of the fetus. But they were not told how the sperm meets the egg. They need to be told the whole story, and not just parts.

\section{Session VI: Monitoring, Information, and Management}

In the sixth session, county and district leaders from four SFPC pilot sites, two of which were in the initial group (Luwan and Jimo), and two of which were in the second group (Xuanwu and Zhuzhou), discussed the innovations that had been introduced in their respective programs to make monitoring, information, and management systems more client-oriented.

\section{Assessing Program Performance from a Quality of Care Perspective}

Zhou Wei, Director of the Family Planning Commission for the Xuanwu District in Nanjing, discussed the differences between assessing program performance from a quality of care perspective and from a population control perspective, and how these perspectives related to past and pres- 
ent work being carried out in Nanjing. In the past, when the goal of the program was population control, quantitative methods were used to collect information on demographic rates. Now that the goal of the program has shifted to meeting clients' needs, a combination of quantitative and qualitative methods are being employed to assess client satisfaction. Four new indicators have been developed to assess program performance: the knowledge dissemination rate, the informed choice participation rate, the follow-up rate, and the client satisfaction rate. A 1998 assessment that used these indicators found that while levels of satisfaction and informed choice were high, levels of knowledge and follow-up were relatively low. The Family Planning Commission is now working to improve the quality of services in light of the findings from the assessment.

\section{Using Information to Serve People Better}

$\mathrm{Xu}$ Baozheng, Director of the Family Planning Commission for the Luwan District of Shanghai, discussed a four-step information system that had been developed by the Commission to better meet clients' needs. First, client information is collected from a variety of sources such as counseling service records, records of people's letters and calls, and population statistics. Second, this information is analyzed regularly. Third, the information is shared with the concerned parties, and fourth, the concerned parties adjust services in line with the new information. In the Luwan District, the information that has been collected, analyzed, and disseminated has been used to meet the needs of a diverse array of clients, including the floating population and high-income clients. Increasing attention is being directed at STD prevention in these two populations as well as others.

\section{Evaluating Client Satisfaction}

Chen Yingxia, Director of the Family Planning Commission of Zhuzhou in Hunan Province, discussed the Commission's efforts in assessing client satisfaction. On the one hand, the Commission wants to know how well it is meeting clients' needs. On the other hand, the Commission wants to enhance clients' awareness of their own health needs and their expectations for service. As in the Xuanwu District of Nanjing, new indicators were developed in Zhuzhou to assess client satisfaction. The new indicators include the IEC satisfaction rate, the technical competence satisfaction rate, the sanitation satisfaction rate, and the provider attitude satisfaction rate. Interestingly, overall satisfaction declined between 1998 and 1999. In 1999, 81 percent of the respondents expressed satisfaction with the 
services that were provided, compared with 89 percent in 1998. One explanation is that clients' expectations for high-quality services are rising.

\section{Village Self-Management in Family Planning}

$\mathrm{Yu}$ Aishan, Director of the Family Planning Commission of Jimo in Shandong Province, discussed the management changes that had been made in the family planning program and the implications of these changes for village residents. While in the past family planning program managers were appointed, village residents now elect them. In addition, village representatives now play an active role in setting local family planning regulations. For its part, the Jimo Family Planning Commission has been engaged in a variety of efforts to strengthen the leadership skills of these new program managers and village representatives. They have, for example, organized leadership-training sessions and study tours. As a result of the Commission's efforts and those of the new family planning program managers and village representatives, village residents have gone from being passive recipients of family planning services to being active participants in managing these services.

\section{Discussion and Comments}

Participants raised issues about the way in which the monitoring, information, and management studies, as well as the project assessment, had been carried out. In particular, concerns were raised about three issues: the selection of quality of care indicators, the sampling of respondents, and the degree to which those who had been selected were able to express their opinions in the presence of government officials. Zhou Wei responded that the selection of indicators must take into account the local context, and it must be tested by practice. The four new indicators that were introduced in the Xuanwu District of Nanjing were useful in their context. It is true that cadres were present when the researchers conducted their interviews. However, the researchers were following a question guide. Also, when clients asked about satisfaction, they were asked to comment on specific services. Chen Huiren added that the evaluation system was still under development, and that work was underway to develop an information feedback system. Once such a system is in place, he added, it will be possible to get data from the computer rather than going out to the field. Finally, Gao Ersheng commented that whatever the evaluation system, it must be rapid, simple, and fair and that therefore cadres' presence should be carefully thought through.

Jay Satia, Executive Director of the International Council on Management of Population Programmes (ICOMP), remarked that though 
the management systems and monitoring play important roles in quality of care programs, we still need to learn more about what form they should take. It is, however, clear that quality improves when the client-provider relationship is the central concern. He noted that while presentations at the sessions had focused on the clients' perspective, it was important to be attentive to providers' concerns as well. Satia also pointed out that the goal of supervision in quality of care programs should be to help providers solve problems. Middle managers should carry out rapid assessments of quality of care by observing service provision and holding discussions with clients and providers. Top-level managers could commission studies to obtain a deeper understanding of program dynamics. Finally, he called for a balance between quantitative and qualitative methods of program evaluation. It is important to know, for example, not only that 90 percent of clients are satisfied, but also why the remaining 10 percent are not. Liu Yongfeng, of the China Family Planning Association, echoed Satia's concerns.

\section{Session VII: Challenges and Prospects}

In the final working session of the symposium, the presenters reviewed the progress that had been achieved to date in implementing quality of care programs and discussed the challenges that lie ahead.

\section{Quality of Care in Family Planning and Reproductive Health:} Strategic Considerations

Zhao Baige, Director of the SFPC's Pilot Project Operations Office, reviewed the results and significance of the quality of care experiment begun in 1995. In a relatively short time, a number of achievements have been realized: the management and technical capacity of family planning personnel has been strengthened; a number of working institutions have been set up to guide the implementation of the program; and international collaboration has been strengthened. As a result of these and other achievements, the quality of care experiment has contributed to both the implementation of the ICPD Programme of Action and the SFPC's family planning strategy.

Zhao then discussed some of the continuing challenges facing the quality of care experiment, and the systems that need to be developed to meet them. Among the challenges are a shortage of qualified personnel, limited financial resources, and inadequate monitoring and evaluation systems. To meet these needs, more attention must be paid to developing the technical 
service system, the management information system, and the monitoring and evaluation system. In addition, more attention needs to be paid to informed choice and the delivery of reproductive health care services.

Lastly, Zhao reiterated the goals and approach of the quality of care experiment. The goals are to control population growth, to improve the population structure, and to promote family planning and socioeconomic development in a coordinated and sustainable manner. To meet these goals, the project seeks to implement a client-centered approach to the provision of family planning and reproductive health services, and to take client satisfaction as the prime indicator of program performance.

\section{Challenges and Prospects}

Xu Bada, Director of the Family Planning Commission of Zhejiang Province, outlined some of the challenges faced by the family planning program in Zhejiang, many of which are related to the introduction of a market economy. Zhejiang has experienced double-digit economic growth in recent years, and as average incomes have risen, so too have people's expectations for services. At the same time, the needs of the "floating population," most of whom are young adults, have become more pressing. In recent years, the number of persons migrating in and out of the province has approached 7 million, and according to a 1999 survey the rate of "out-of-plan" births in these two groups is 10 percent higher than the provincial average.

$\mathrm{Xu}$ outlined the program's future goals and objectives. At present, approximately 40 counties have introduced quality of care programs. By 2005, it is hoped that all counties in the province will have done so. To realize this goal, concerted efforts are underway to improve staff, facilities, and IEC. The provincial government, Xu added, will no longer assign birth quotas to townships. Instead, townships will formulate their own plans, and couples may plan their first birth according to their own wishes.

\section{Seizing the Opportunity to Promote Quality of Care}

Zhu Hongchun, Party Secretary of Yandu County, discussed the characteristics of the family planning program in Yandu before and after the introduction of the pilot project. Before its introduction, the program relied on administrative measures to ensure people's compliance, services were limited to contraception, and clients were largely women of childbearing age. After the introduction of the pilot project, improving the quality of care became a prime interest of the local government, integrated family planning and reproductive health services were introduced, and efforts were made to broaden the clientele. As a result of these and other 
efforts, clients express greater satisfaction with the program. Economic factors, Zhu added, have become a driving force in the family planning program, and in the future more attention should be paid to establishing a mechanism for family planning program management that is consistent with the development of a market economy.

\section{Discussion and Comments}

Participants discussed the relationship of the quality of care project to the government's family planning policy. Xu Bada said that he thought the project was consistent with the SFPC's strategic goals. Although the Family Planning Commission cooperates with the departments of social security and public health, family planning services are still its first priority. Zhao Baige added that quality of care is a handle for the program, a way to bring together many related elements.

Participants also discussed how to sustain momentum for the project. Zhu Hongchun responded that the most important thing is to show concern for the needs, including political needs, of the program staff. He cited the case of Madame Liu Gaoying, the former director of the Yandu County Family Planning Commission, whom the local government had nominated for consideration as a model worker. At first, they encountered resistance. Later, after they argued for her candidacy, citing the instrumental role she had played in initiating the quality of care project in Yandu, she received recognition from the provincial government as a model worker.

Zhu added that he had two concerns about scaling up the pilot experiment: (1) how it would be possible to carry out the project without external support, and (2) how much value could be put on what had been achieved so far, given the way the research had been carried out. Xiao Shaobo, Vice-Director, Department of Science and Technology of the SFPC, said that an evaluation initiated from the field could not be judged in the same way as an academic paper, and that little money had gone to the county to carry out the project.

Tan Lin, Professor at the Population Institute of Nankai University in Tianjin, said that the changes that had taken place in the family planning program in the past few years were dramatic, and were especially important for women's health and development. Still, much remains to be done to advance women's status. To illustrate this point, Tan cited two examples. The first involved a woman who reluctantly gave birth to a second child after her husband pressured her to do so. The second involved a visit she made to a "population school" in Shaanxi. There she observed two classes, one for men and one for women. While the topic of discussion in 
the men's class was "production," in the women's class discussion centered on "reproduction." She added that there needs to be another lesson, one on gender equality and shared responsibility.

Joan Kaufman, Reproductive Health Program Officer at the Ford Foundation in Beijing, noted that the symposium was evidence of the enormous change that had taken place in China and its family planning program in the past few years. In the early 1990s when Kaufman wrote an article on the quality of care in rural China, it was a novel topic. Now what began as a small experimental project in 1995 has expanded to some 660 counties.

Quality of care, Kaufman continued, is not about money, it is about changing attitudes and having a client-driven program. Little of the money that Ford has provided has gone to the local level. The commitment of local leaders has made the project successful. In the future, more attention needs to be devoted to engaging women's groups in the process of improving the quality of care. The question is not how to control fertility but rather how to meet people's needs.

Susan Greenhalgh, Associate Professor of Anthropology at the University of California at Irvine, commented on China's recent efforts to reorient its family planning program. She noted that although the quality of care experiment represents an important first step, continued progress requires that a careful analysis of the current situation be undertaken. She suggested that it is important to consider "four contradictions." The first contradiction is between the connotations of the English phrase "quality of care" and the Chinese expression youzhi fuwu. The two expressions, she said, belong to different conceptual worlds. The second contradiction is between the old and the new. Without a serious analysis of the problems of the past, it is possible that those same mistakes may be repeated. The third contradiction is between the higher and lower levels. How, Greenhalgh asked, is it possible to create a space in which people can truly express their preferences when official population policy covers every aspect of childbearing? The fourth contradiction is between men and women. Although repeated references have been made to making women the masters of birth planning, they (and their female offspring) bear a disproportionate burden in keeping China's fertility rate down.

\section{Plenary Session}

Joan Kaufman, Reproductive Health Program Officer at the Ford Foundation in Beijing, outlined several areas where work remains to be 
done to further improve the quality of care in China. She enumerated several issues related to the project's expansion to less developed areas, including: the importance of assessing client need, developing asepsis and service protocols, and introducing informed choice. She also suggested that in less developed areas, the family planning sector should assume responsibility for the prevention, diagnosis, and treatment of RTIs because the health sector was too overburdened to do so. To accomplish these and related goals, more attention needs to be paid to improving coordination within the SFPC as well as with outside institutions.

Kaufman elaborated on the constraints to informed choice in China, and cited some examples of projects that have begun to address these issues. The constraints to informed choice include program bias for paritydriven method provision; provider bias for long-acting provider-dependent methods; and an authoritarian doctor-patient relationship, which assumes that the doctor knows what is best for a client. The SFPC pilot projects in Deqing, as well as WHO-supported projects in Taicang and Rudong in Jiangsu, demonstrate that expanding contraceptive choice with counseling results in improved contraceptive continuation. Kaufman noted that it was especially important to publicize these findings to policymakers in China to demonstrate the feasibility of introducing informed choice.

Kaufman also discussed the need to make greater use of participatory approaches to needs assessment, on the grounds that clients know their own problems best. She also cautioned against using clinic-based service statistics to identify reproductive health needs for program planning because service seeking for these conditions is often low. Finally, Kaufman called for reform of the evaluation system, especially the need to decouple the link between program evaluation and cadre evaluation. Doing so, she maintained, would change the "signals" to cadres and make clear that quality and client satisfaction matter.

George Brown, Vice President, International Programs Division, the Population Council, pointed out that China has initiated an ideological shift away from a demographically driven population strategy, and has made major strides in implementing a quality of care approach to the provision of reproductive health services. Most importantly, the family planning program has listened to the needs and desires of clients, especially women, in attempting to adapt to local conditions the major elements of the Cairo Programme of Action.

There are, however, many challenges ahead, and much work remains to be done to change the underlying ideology of the program, as well as its work style. Most importantly, it is essential to continue to move away 
from a demographically oriented program and toward a client-centered one. Brown noted that both approaches had been expressed in various presentations during the symposium. However, the quality of care approach must increasingly take precedence as the program expands and matures. Demographic issues remain important for planning purposes at the central level, but should not prevail at the service level or in interactions between providers and clients. More attention also needs to be given to meeting the special needs of specific populations such as men, adolescents, and the "floating population." Women have the most important reproductive health needs of all, for it is they who bear the greatest burden. They also often lack the power to speak out regarding their needs and aspirations. Therefore, not only must their needs be listened to but women also must be empowered so that they can play a more active role within their family and community, protect themselves from STIs and other reproductive health problems, and play an equal role with their partners in child care as well as family formation. Brown noted that as the Chinese commitment to quality of care expands, there would be great interest worldwide in learning about their experience. He believed that, with careful documentation, China can explain its new strategy and its successful implementation, and can overcome some of the negative views of the Chinese population program. More international exchange is important for China, and especially for the rest of the world.

Junko Sazaki, Deputy Representative of UNFPA's Beijing Office, described the aims, accomplishments, and challenges of carrying out the UNFPA's program in China. The Fourth UNFPA China Program is intended to play a catalytic role in shifting the focus of reproductive health and family planning services from an administratively oriented approach to a client-centered one. The Reproductive Health/Family Planning Project in particular is aimed at assisting the State Family Planning Commission and the Ministry of Health in strengthening reproductive health and family planning services in 32 counties in 22 provinces to better meet the needs of individuals and couples through promoting quality of care. Sazaki noted that the project has been implemented successfully and that UNFPA is impressed with the government's sincere effort to remove birth quotas and family planning targets in the project sites, and with its strong commitment to successfully implementing the project. Still, considerable challenges exist in implementing the project and expanding it in the future. Although government funding for family planning is very high, regional economic disparities and low-level funding for the health sector pose challenges to providing high-quality integrated reproductive health services in 
poor areas. Also, considerable efforts need to be made in providing integrated reproductive health services by improving the collaboration between the State Family Planning Commission and the Ministry of Health. In order to sustain the successful developments in quality of care, improvements in the funding mechanisms and management systems should be introduced.

\section{Closing Session}

Zhang Weiqing, Minister of the State Family Planning Commission (SFPC), extended his thanks to all participants for their work in making the International Symposium on Quality of Care in China a success. He then reviewed the achievements of the SFPC pilot project on quality of care in family planning, and reaffirmed China's commitment to gradually expanding the quality of care approach to the country at large. He also noted that a report to the State Council would be made detailing the ideas and suggestions that had emerged from the symposium. Up to now, quality of care projects have been carried out in some 660 counties, municipalities, and districts. As a result of the technical assistance from the departments concerned, as well as the assistance of the Ford Foundation, the Population Council, and the University of Michigan, the network for providing family planning services has been strengthened and the quality-oriented management responsibility system has been improved. Together with the implementation of the poverty-alleviation program and the social insurance system, great efforts have been made to provide quality family planning and reproductive health services. It is clear that the family planning program has improved and is now more welcomed by the people.

The delivery of high-quality care is also an important step toward fulfilling the commitment made by the Chinese Government in support of the ICPD Programme of Action. In accordance with Premier Zhu Rongji's requirement, the SFPC is now formulating China's Plan of Action on Population and Development for the 21 st Century to implement the Cairo Programme of Action and the decisions of the most recent Special Session of the UN General Assembly. In addition to calling for the training of more capable government staff, the Plan of Action will have a far-reaching impact on the structural reform of the family planning program.

Zhang noted that the quality of care approach should be implemented throughout the country, especially in central and western China and other less developed areas. Services should be provided in an integrated 
way with attention to people's diverse needs, including poverty alleviation, social security, and other related issues. The implementation of a quality of care approach requires the participation of the government, nongovernmental organizations, and the people themselves. Zhang concluded that the SFPC is convinced that implementation of a quality of care approach will lead to the success of China's population and family planning program, and that China's experience will be of great import for the world at large. 


\section{APPENDIX \\ Excerpts from Minister Zhang Weiqing's \\ Meeting with International Participants}

Ruth Simmons: I would like to make some suggestions related to the assessment. I think you are aware that we all express great admiration for China's achievements to date. Still, as several speakers have pointed out, the transition to a quality of care approach is as yet incomplete. I think of it as a beautiful child that requires nurturing. Also, with regard to expansion, it is important to recognize that not only are people's needs different but also that service capacity differs from place to place. Therefore, as you seek to expand, you should do so in an incremental way. You should also document your work so that you may learn from the process of expansion.

Zhang Weiqing: I respect what you have said in terms of expansion and I hope that we can work together to realize these goals.

Jay Satia: I would like to suggest a few things with regard to the issue of expansion. First, the commitment of top management is key to the success of the project. Second, for many problems the various SFPC departments need to work together. Third, actions must be documented so that others can learn from your experiences.

Zhang Weiqing: That's right. Very good.

Judith Bruce: I'd like to point out one other ally in designing and sustaining quality of care programs. Policy and managers are the fire from above, but women and community organizations are the fire from below. I encourage you to work with women's groups at the local level. They can help you to gain information about clients and their needs.

Barbara Pillsbury, Cofounder of the Pacific Institute for Women's Health: With the growth of a market economy and globalization, women often fall behind. This is true not only in China but throughout the world. In China, there is also a growing gap between the eastern and western parts of the county. This has important implications for program expansion. It will be important to work closely with other sectors to promote women's empowerment.

Zhang Weiqing: I quite agree. In fact, when we carry out family planning work we cooperate with other departments. And at the village level, we do a lot with women's groups. My predecessor, Madame Peng Peiyun, is now Chair of the All China Women's Federation (ACWF). 
Also, I'd like to inform you that after six days and six nights, the US and China reached an agreement about China's entry into the WTO. China's government also pushed for the development of the western part of China. As we work out a plan for the project's expansion, all these things should help.

Saroj Pachauri: I've learned a lot in the past few days. Countries in South and Southeast Asia have a lot to learn from the Chinese experience. It is especially important that we develop creative mechanisms to work together and share our experience.

Peter Fajans, Scientist in the Department of Contraceptive Technology Introduction and Transfer at the World Health Organization: One of the things that we have learned at WHO is the importance of involving multiple stakeholders in the assessment process. We have also found that by talking to all kinds of people, we not only conduct a better assessment, we also get new ideas about how to move the program forward.

Zhang Weiqing: I'd like to add something. Frankly speaking, international cooperation has been limited due to many complicated reasons such as misunderstanding of the one-child policy, and allegations of coercion and human rights violations. Actually, we want more international collaboration if others are also interested. I think the Population Council and the University of Michigan are very brave in leading the way.

Susan Greenhalgh: There is also a fifth contradiction. According to the ICPD Programme of Action, clients should speak out and providers should respond to their expressed needs. But you said that policy would not change. How then do we deal with this contradiction?

Zhang Weiqing: China's population policy is not a one-child policy. In the majority of rural areas, couples can have two children. In some remote mountainous areas they can have three, and in some minority areas they can even have four. In the world everything is subject to restrictions. Everywhere in the world you have to follow the rules. Even in this meeting, we set a no-smoking rule. So, for births we also need rules. China's population policy is good for the state and the people. Still, we acknowledge that there have been problems in the implementation of the program, that in some areas human rights violations have occurred. But have no doubt, when we in the government see a problem we will address it. 
Judith Bruce: I have three points I'd like to make. First, men need to share the contraceptive burden. Second, I think it would be worthwhile to analyze what the potential impact of lifting the one-child policy might be. In this way, you could identify those areas where the level of socioeconomic development is relatively low and policy implementation has been strong. These are the areas that would be most vulnerable to a population increase if the policy were lifted. And lastly, many sectors have a role to play in developing client-centered programs.

Zhang Weiqing: You are quite right. Many sectors have a role to play.

Also present at the meeting with the Minister were Baige Zhao of the SFPC, directors of various departments of the SFPC, Joan Kaufman of the Ford Foundation, and Baochang $\mathrm{Gu}$ and Diana Szatkowski of the Population Council. 